\title{
GROUND SUBSIDENCE ALONG SHANGHAI METRO LINE 6 BY PS-InSAR METHOD
}

\author{
Jicang Wu, Minyan Liao, Naiyi Li \\ College of Surveying and Geo-Informatics, Tongji University, Shanghai, 1733515@tongji.edu.cn
}

Commission III, WG III/3

KEY WORDS : Ground subsidence, Shanghai Metro Line 6, PS-InSAR, COSMO-SkyMed, Envisat ASAR

\begin{abstract}
:
With the rapid development of urban economy, convenient, safe, and efficient urban rail transit has become the preferred method for people to travel. In order to ensure the safety and sustainable development of urban rail transit, the PS-InSAR technology with millimeter deformation measurement accuracy has been widely applied to monitor the deformation of urban rail transit. In this paper, 32 scenes of COSMO-SkyMed descending images and 23 scenes of Envisat ASAR images covering the Shanghai Metro Line 6 acquired from 2008 to 2010 are used to estimate the average deformation rate along line-of-sight (LOS) direction by PS-InSAR method. The experimental results show that there are two main subsidence areas along the Shanghai Metro Line 6, which are located between Wuzhou Avenue Station to Wulian Road Station and West Gaoke Road Station to Gaoqing Road Station. Between Wuzhou Avenue Station and Wulian Road Station, the maximum displacement rate in the vertical direction of COSMO-SkyMed images is $9.92 \mathrm{~mm} /$ year, and the maximum displacement rate in the vertical direction of Envisat ASAR images is $-8.53 \mathrm{~mm} / \mathrm{year}$. From the West Gaoke Road Station to the Gaoqing Road Station, the maximum displacement rate in the vertical direction of COSMO-SkyMed images is $-15.53 \mathrm{~mm} / \mathrm{year}$, and the maximum displacement rate in the vertical direction of Envisat ASAR images is $-17.9 \mathrm{~mm} / \mathrm{year}$. The results show that the ground deformation rates obtained by two SAR platforms with different wavelengths, different sensors and different incident angles have good consistence with each other, and also that of spirit leveling.
\end{abstract}

\section{INTRODUCTION}

It was found that land subsidence in Shanghai began in 1921 by repeated leveling measurements. From 1921 to 1948, the average subsidence in Shanghai was $639 \mathrm{~mm}$, and the maximum cumulative subsidence was $1136 \mathrm{~mm}$ (Gong, 2006). Traditional methods for monitoring land subsidence include leveling and GPS measurements. With the development of global satellite technology, high-precision, short-revisited SAR (Synthetic Aperture Radar) satellites are launched to obtain SAR images, and interferometric SAR(InSAR) can can be used to obtain large-scale, high-precision ground deformation information. For overcoming spatiotemporal decorrelation and atmospheric delay, Ferretti et al.(2001) proposed PS-InSAR (Permanent Scatterers InSAR) method. Nowadays, PS-InSAR technology has been widely used in urban land subsidence monitoring and urban rail transit deformation monitoring. In 2012, Liao et al. used Envisat ASAR images and TerraSAR-X images to get the deformation rate of Shanghai City (Liao et al.,2012). In 2012, Perrissin et al. used COSMO-SkyMed images to monitor the deformation of tunnels and highways in Shanghai. (Perrissin et al.,2012). In 2014, Ge et al. used COSMO-SkyMed images to study the spatiotemporal variation characteristics of ground subsidence in the construction and operation period of Shanghai Metro Line 10. (Ge et al.,2014). In 2014, Jia et al. processed Envisat ASAR data and obtained displacement information along the Beijing Metro Line 15. (Jia et al.,2014). In 2016, Qin et al. used TerraSAR-X images to carry out subsidence measurements in Shanghai to obtain the overall displacement information of the rail transit network. (Qin et al.,2016).

In this paper, two sets of SAR data with different wavelength are used to obtain the line-of-sight(LOS) deformation rate along Shanghai Metro Line 6 from 2008 to 2010 by PS-InSAR technology. Then, comparing the deformation results of the two SAR platforms and the precision leveling data.

\section{PS-INSAR DATA PROCESSING}

Select one of N SAR image as the master, and the rest of them are registered with the master to form $\mathrm{N}-1$ interferometric pairs. After removing the flatten effect, the referenced DEM is used to remove the topographic phase and the differential interferograms are generated.

The permanent scatterers (PS) are selected using the amplitude dispersion index proposed by Ferretti et al. (2001). When the number of SAR images is larger than 30 , the stability of the PS points' amplitude can be used to present the stability of the phase (Ferretti et al.,2001). Reliable phase information can be obtained at these discrete PS points, from which the atmospheric phase and deformation phase can be separated to obtain accurate ground deformation and DEM information.

After estimating the linear deformation and the DEM error at each PS point, subtracting them from the initial differential interferometric phase, the residual phase can be obtained, which mainly includes the nonlinear deformation phase, the atmospheric phase, and the noise phase. In the residual phase, the atmospheric phase and the nonlinear deformation phase can be separated by high-pass temporal filtering and low-pass spatial filtering so as to get the land subsidence rate. The detailed PS-InSAR data processing workflow is shown in Figure 1. 


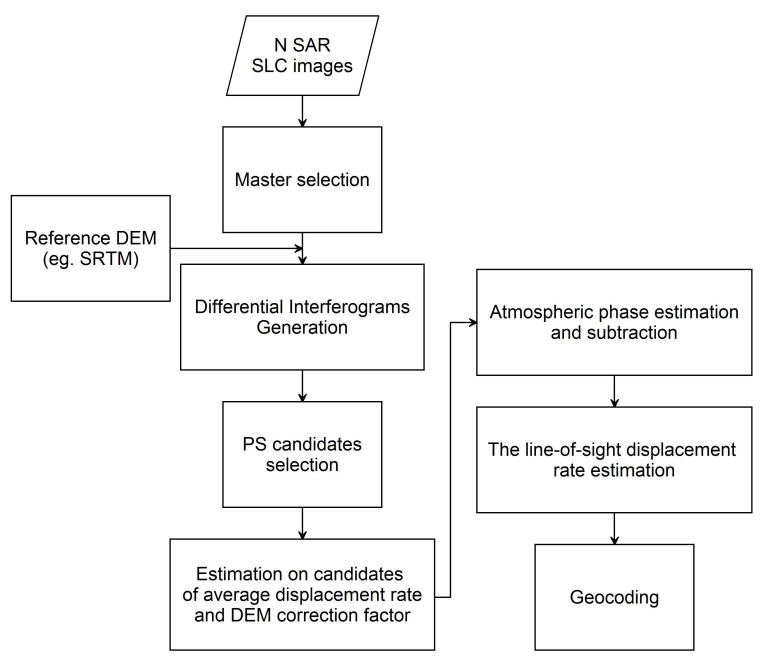

Figure 1. PS-InSAR data processing workflow

\section{STUDY AREA AND DATA RESOURCE}

\subsection{Study Area}

Shanghai, located in the mouth of the Yangtze river, is one of the first cities in China to face land subsidence. Shanghai is a typical soft soil foundation city. The ground subsidence caused by over-exploitation of groundwater in the early 20th century. Another significant reason for land subsidence in Shanghai today is the construction of high-rise buildings and underground works. The first line of Shanghai subway was operated in 1993. Up to March 2018, 16 Metro lines is running (Line 1-13, Line 16-17 and the maglev) in Shanghai. In addition, 5 lines are being expanded and 4 new lines are planned.

Shanghai Metro Line 6 with a length of 36.1 kilometers, starting from Gangcheng Road to the Oriental Sports Center, throughout Shanghai Pudong New District. The Metro Line 6 went into operation in December 29, 2007, and the Oriental Sports Center went into operation in April 12, 2011. Wulian Road station and 9 stations to its north are elevated stations, and the other 19 stations in the south of Wulian Road station are underground stations. It connects Waigaoqiao Free Trade Zone, Gaoqiao Residential District, Jinqiao Development Zone, Lujiazui Financial and Trade Zone, Liuli Modern Life Park, Sanlin Residential District, Oriental Sports Center and other important functional and residential areas in Pudong New District.

\subsection{Data Resource}

In this paper, 32 scenes of X-band high-resolution COSMOSkyMed descending images and 23 scenes of C-band mediumresolution Envisat ASAR images are used to estimate the average displacement rate. The time span of SAR images acquired ranges from 2008 to 2010. The coverage of the COSMO-SkyMed images is $28 \mathrm{~km} * 14 \mathrm{~km}$. All the images are obtained with the descending orbit and the radar sight angle is 23.96 degrees. The coverage of the Envisat ASAR images is $27 \mathrm{~km} * 20 \mathrm{~km}$, and all images are obtained with the ascending orbit and the radar sight angle is 22.77 degrees. The coverage of the two sets of experimental data is shown in Figure 2.

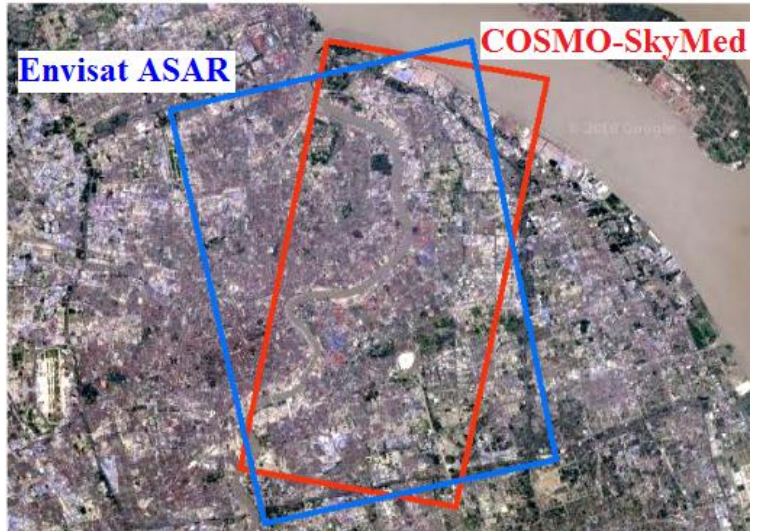

Figure 2. Experimental data coverage (satellite image from Google)

The COSMO-SkyMed satellite operates on the near polar sun synchronous orbit, with a height of 619.6 kilometers, and the orbit inclination of 97.86 degrees. There are many different resolution imaging modes. The orbit period is 16 days, and the highest resolution can reach up to 1 meters. In the PS-InSAR data processing, considering the effects of spatiotemporal baseline distribution, Doppler center frequency, and water vapor, we choose 2009-08-25 image as the master, and generate 31 interferometric data pairs. The spatiotemporal baseline distribution of the interferometric pair is shown in Figure 3. The spatial baseline is from $-728.142 \mathrm{~m}$ to $701.165 \mathrm{~m}$, and the time baseline is from 16 days to 464 days.

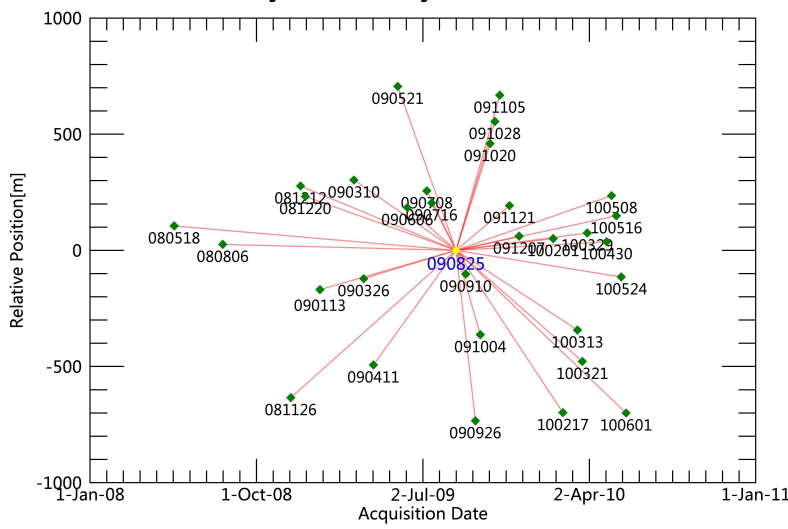

Figure 3. The spatio-temporal baseline of 32 Cosmo-SkyMed interferometric pairs

Envisat is a medium-resolution $\mathrm{C}$ band radar satellite. 23 scenes of the Envisat ASAR images are used for taking PS-InSAR in this experiment. After considering the effects of spatiotemporal baseline distribution, Doppler center frequency, and water vapor, the 2009-08-24 image was selected as the master. A total of 22 interferometric pairs are generated. The spatiotemporal baseline distribution is shown in Figure 4. The spatial baseline ranges from $-428.604 \mathrm{~m}$ to $186.632 \mathrm{~m}$, and the time baseline ranges from 35 days to 595 days. 


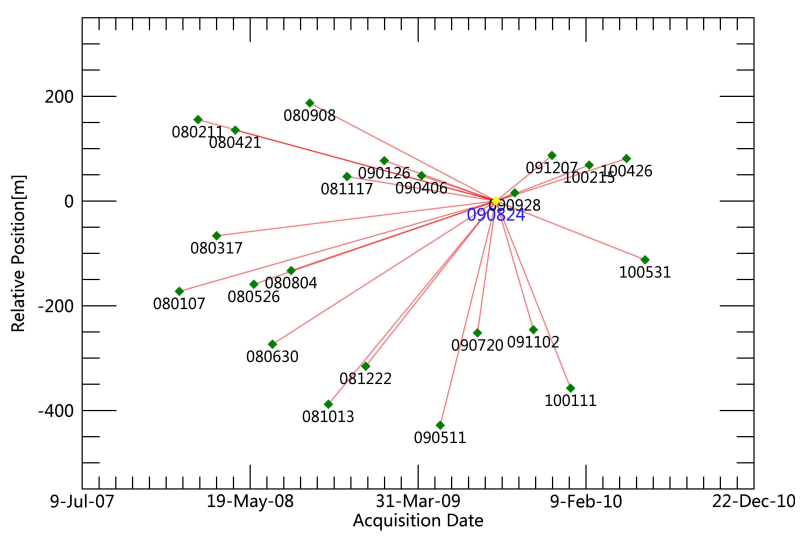

Figure 4.The spatio-temporal baseline of 23 Envisat interferometric pairs

\section{EXPERIMENTAL RESULTS AND ANALYSIS}

\subsection{EXPERIMENTAL RESULTS}

The above experimental SAR images are processed based on PS-InSAR technology. In order to ensure the stability of the PS points in the time domain, this experiment adopts the amplitude deviation index method to select the PS points. According to the coordinates of Shanghai Metro Line 6, the PS points in the range of 50 meters on both sides of the line are screened out. Then, the ground subsidence results obtained by the two SAR platforms are compared and analyzed.

13,729 PS points are obtained by processing 32 scenes of COSMO-SkyMed images. The average deformation rate map of the Metro Line 6 is obtained by PS-InSAR results, and it is shown in Figure 5. It can be seen from Figure 5 that the maximum subsidence rate of the elevated ground section from Wuzhou Avenue Station to Wulian Road Station is $-6 \mathrm{~mm} / \mathrm{year}$ approximately, and the maximum subsidence rate of the underground section from West Gaoke Road Station to Gaoqing Road Station is about $-15 \mathrm{~mm} /$ year.

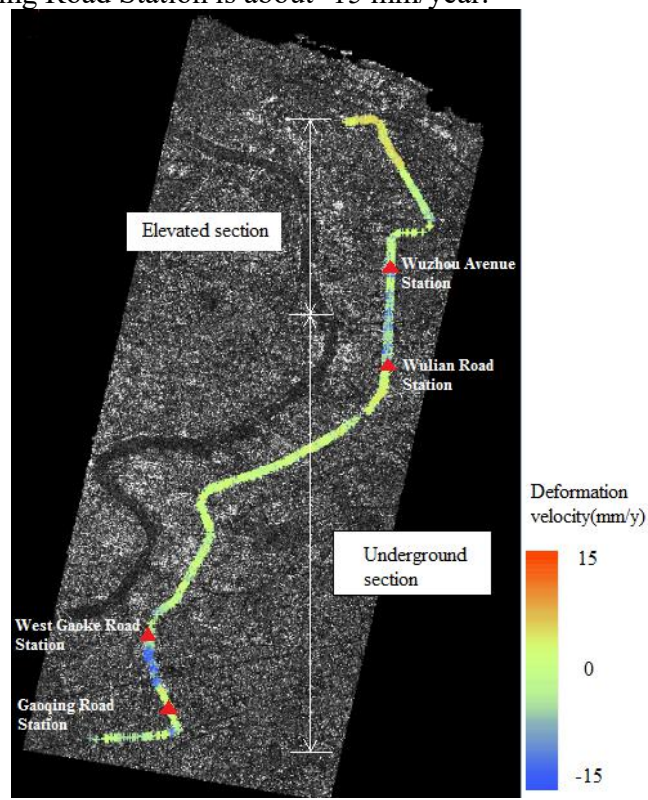

Figure 5. The deformation rate along Shanghai Metro Line 6 by 32 scenes of Cosmo-SkyMed descending images
6,091 PS points are obtained by processing 23 scenes of Envisat ASAR images. The average deformation rate map of the Metro Line 6 is shown in Figure 6. As can be seen in Figure 6, the maximum subsidence rate of the elevated section is -10 $\mathrm{mm} /$ year approximately, and the maximum subsidence rate of the underground section is $-25 \mathrm{~mm} /$ year approximately. So, there are two significant subsidence areas, which are located in the elevated section from Wuzhou Avenue Station to Wulian Road Station and the underground section from West Gaoke Road Station to Gaoqing Station.

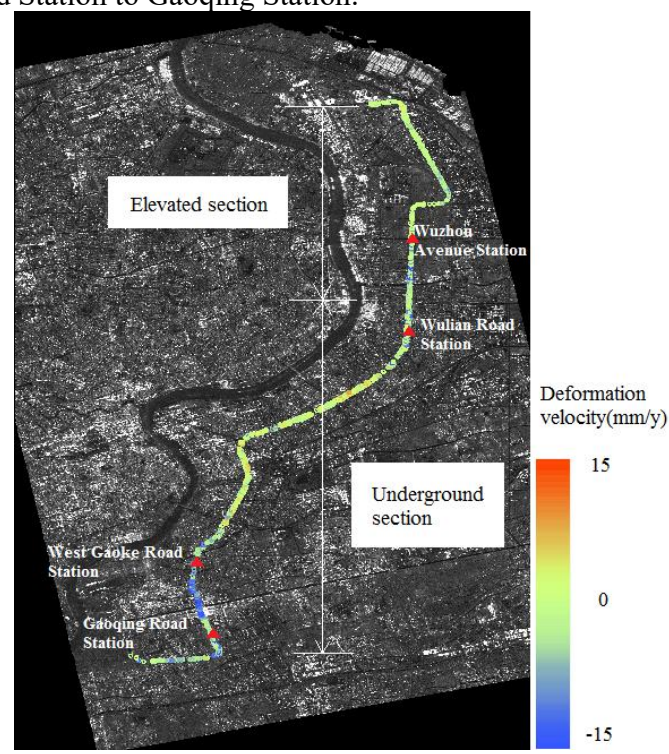

Figure 6. The deformation rate along Shanghai Metro Line 6 by 23 scenes of Envisat ASAR images

From the overall deformation distribution of the two maps, the subsidence of the northern section of the Shanghai Metro Line 6 (the elevated section) is relatively small, and the subsidence of the southern section (the underground section) is relatively large.

\subsection{COMPARISION OF TWO SAR PLATFORMS}

According to the above PS-InSAR results, the ground subsidence from Wuzhou Avenue Station to Wulian Road Station is significant and the total length of this segment is about 3.5 kilometers. 30 PS points on this segment are selected for comparing the deformation rates in the vertical direction by the two SAR platforms. The result of the comparison is shown in Figure 7. In this segment, the gound subsidence rate obtained by COSMO-SkyMed varies from $-9.92 \mathrm{~mm} /$ year to 0.69 $\mathrm{mm} /$ year, and varies from $-8.53 \mathrm{~mm} /$ year to $1.13 \mathrm{~mm} /$ year obtained by Envisat ASAR data. The trend of ground subsidence rate by the two sets of SAR data has good consistency.

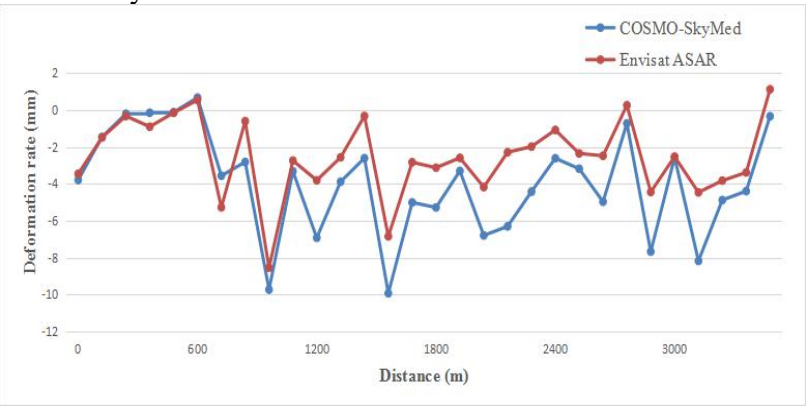

Figure 7. The displacement rate in the vertical direction (from Wuzhou Avenue Station to Wulian Road Station ) 
In Fig.5 and Fig.6, the deformation from West Gaoke Road Station to Gaoqing Station is even more significant and the total length of this segment is about 3 kilometers. 20 PS points on this segment are selected to compare the deformation rates in the vertical direction by the two SAR platforms. The result of the comparison is shown in Figure 8. In this segment, the average deformation rate in the vertical direction by the COSMO-SkyMed data varies from $-15.53 \mathrm{~mm} /$ year to -0.53 $\mathrm{mm} /$ year, and varies $-17.9 \mathrm{~mm} /$ year to $-3.12 \mathrm{~mm} /$ year by Envisat ASAR data. The segment is located in Sanlin residential district with many buildings and metro lines. Therefore, the ground subsidence is probably due to the construction of buildings and the operation of metro lines. In Fig.8, the trend of subsidence rate by the two sets of SAR data are also in good consistency.

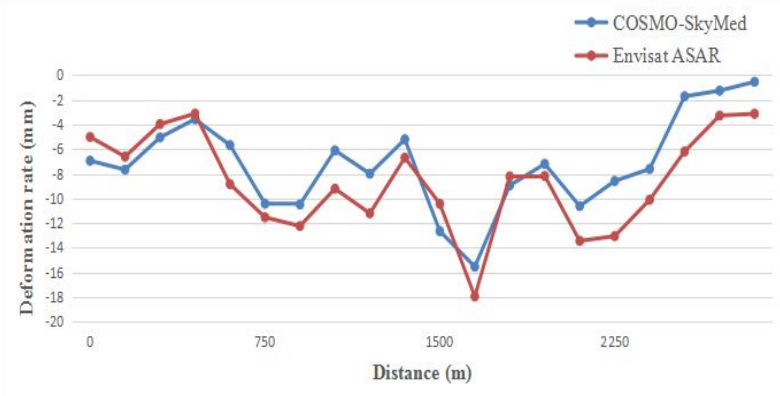

Figure 8. The displacement rate in the vertical direction of the experiment area(from Gaoke West Road Station to Gaoqing Station )

\subsection{COMPARISION WITH LEVELING}

In the spirit leveling data, there are two precision benchmarks, $\mathrm{A}$ and $\mathrm{B}$, near the experimental segment which from West Gaoke Road Station to Gaoqing Station, and the observation period is from 2006 to 2011. Benchmark A (Lat: $31.18245948^{\circ}$, Lon: $121.5034146^{\circ}$ ) is close to West Gaoke Road Station and is about 150 meters away from Shanghai Metro Line 6 . Benchmark B (Lat: $31.17476137^{\circ}$, Lon: $121.5058869^{\circ}$ ) is close to Dongming Road Station, and is about 50 meters away from Shanghai Metro Line 6. The elevation change of $\mathrm{A}$ in the observation period is $-28.3 \mathrm{~mm}$, and is $-30.35 \mathrm{~mm}$ of $\mathrm{B}$. If we assume that the rate of elevation change over the five years is stable, then the average rate of $\mathrm{A}$ is $-5.66 \mathrm{~mm} / \mathrm{year}$, and the average rate of $B$ is $-6.07 \mathrm{~mm} /$ year.

10 closest PS points are chosen around A and B respectively. The LOS displacement time-series of the 10 PS points by COSMO-SkyMed SAR data are drawn in Fig.9. Figure 9 (a) is the LOS displacement time series of the 10 PS points near benchmark, and the accumulated LOS displacement is about -10 $\mathrm{mm}$. Figure 9 (b) is the LOS displacement time series of the 10 PS points near the benchmark $\mathrm{B}$, and the accumulated LOS displacement is about $-15 \mathrm{~mm}$.

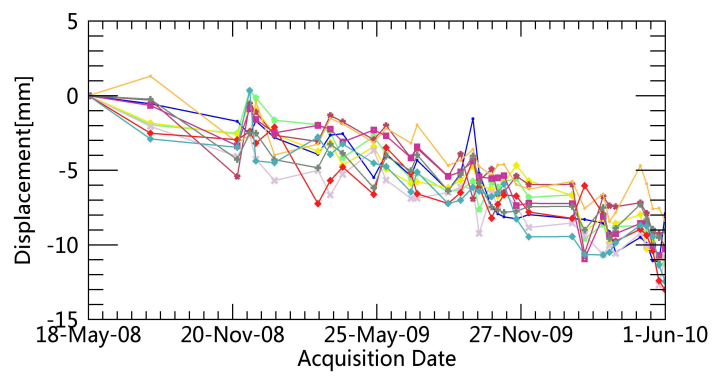

(a)

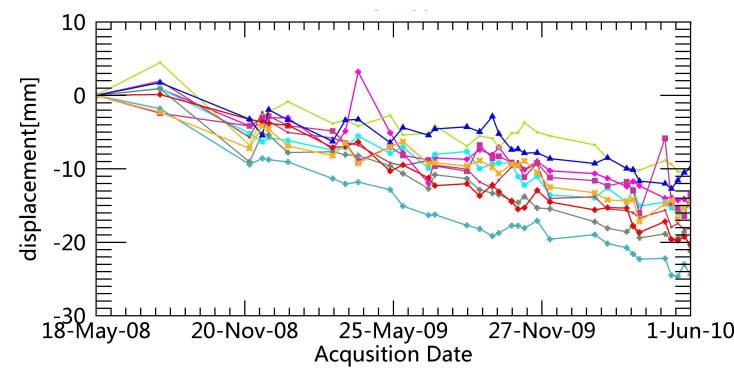

(b)

Figure 9. LOS displacement time series of the 10 chosen PS points (a) Nearby benchmark A; (b)Nearby benchmark B

\begin{tabular}{|c|c|c|c|}
\hline $\begin{array}{c}\text { Deformation } \\
\text { rate } \\
\text { (mm/year) }\end{array}$ & $\begin{array}{c}\text { Leveling } \\
\text { (Date: } \\
\text { 2006-2011) }\end{array}$ & $\begin{array}{c}\text { COSMO-SkyMed } \\
\text { (Date: 2008- } \\
\text { 2010) }\end{array}$ & $\begin{array}{c}\text { Envisat ASAR } \\
\text { (Date: 2008- } \\
\text { 2010) }\end{array}$ \\
\hline A & -5.66 & -3.65 & -4.62 \\
\hline B & -6.07 & -9.92 & -7.29 \\
\hline
\end{tabular}

Table1. Comparing the average displacement rate in vertical direction

Table 1 shows the average displacement rate in the vertical direction by leveling data, COSMO-SkyMed data and Envisat ASAR data. The average deformation rate of the benchmark A is $-5.66 \mathrm{~mm} / \mathrm{year}$, the COSMO-SkyMed data result is -3.65 $\mathrm{mm} /$ year, and the Envisat ASAR data result is $-4.62 \mathrm{~mm} / \mathrm{year}$. The average deformation rate of the benchmark $\mathrm{B}$ is -6.07 $\mathrm{mm} /$ year, the COSMO-SkyMed data result is $-9.92 \mathrm{~mm} /$ year, and the Envisat ASAR data result is $-7.29 \mathrm{~mm} /$ year. It can be seen that the ground subsidence rate obtained by PS-InSAR is consistent with that of spirit leveling.

\section{CONCLUSIONS}

In this paper, we uses 32 COSMO-SkyMed descending images and 23 Envisat ASAR images between 2008 to 2010 to obtain the ground subsidence rates along Shanghai Metro Line 6. The characteristics of the significant subsidence sections and timeseries deformation of PS points around the spirit leveling benchmarks are analyzed. The results show that the ground subsidence rates obtained by the two SAR platforms have good consistency, and are also consistent with that of spirit leveling. In addition, the number of PS points in $\mathrm{X}$ band high-resolution COSMO-SkyMed images is twice more than that of $\mathrm{C}$ band Envisat ASAR images, showing the superiority of $\mathrm{X}$ band highresolution SAR images in urban land subsidence monitoring. In general, the ground subsidence of elevated section of the Metro Line 6 is smaller than that of the underground section. The significant subsidence area are located in two segments, one from Wuzhou Avenue Station to Wulian Road Station and the other from West Gaoke Road Station to Gaoqing Road Station. There are dense residential districts and multiple metro lines in the two significant subsidence area. Therefore, the increase of metro lines and residential capacity, and the construction of the underground infrastructure near the metro line are believed to be the main reasons for the ground subsidence.

\section{ACKNOWLEDGEMENTS}

This research was supported by the State Key Development Program for Basic Research of China (No. 2013CB733304), the DAAD Thematic Network Project(ID:57173947) and the National Science Foundation (No. 41674003). We thank the 
Beijing Vastitude Technology Co., Ltd. for providing the SAR images.

\section{REFERENCES}

Ferretti, A., Prati, C., and Rocca, F., 2001. Permanent scatterers in SAR interferometry. IEEE Transactions on Geoscience \& Remote Sensing, 39(1), pp. 8-20.

Ferretti, A., Prati, C., and Rocca, F., 2000. Nonlinear subsidence rate estimation using permanent scatterers in differential SAR interferometry. IEEE Transactions on Geoscience \& Remote Sensing, 38(5), pp. 2202-2212.

Gong, S., 2006. Review on Land Subsidence Research of Shanghai. Shanghai Geology. (in Chinese)

Ge, D., Zhang, L., and Wang, Y, et al., 2014. High-resolution InSAR Monitoring and Analysis of Land Subsidence Effect in the Construction and Operation of Shanghai Metro Line 10. Shanghai Land and Resources, pp. 62-67.(in Chinese)

Jia, X., Gong, H., and Chen, Y., et al., 2014. Analysis of the Effect of Uneven Land Subsidence on the Operation of Beijing Metro Line 15. Remote Sensing Information, pp. 58-63.(in Chinese)

Liao, M., and Lin, H., 2003. Radar Interferometry - Principle And Signal Processing Base. Beijing: The Mapping Publishing Company .(in Chinese)

Liao, M., Pei, Y., and Wang, H., et al., 2012. Subsidence Monitoring in Shanghai Using the PSInSAR Technique. Shanghai Land \& Resources.(in Chinese)

Perissin, D., Wang, Z., and Lin, H., 2012. Shanghai subway tunnels and highways monitoring through Cosmo-SkyMed Persistent Scatterers. IPSRS Journal of Photogrammetry \& Remote Sensing, 73(3), pp. 58-67.

Qin, X., Yang, M., and Wang, H.,et al., 2016. Application of high resolution PS-InSAR in the detection of deformation characteristics of rail transit. Acta Geodaetica et Cartographica Sinica, 45(6), pp. 713-721.(in Chinese) 